\title{
Идентификация поврежденных участков леса сибирским шелкопрядом на основе данных Landsat-8
}

\section{ГОРОШКО А.А., СУЛЬТСОН С.М., МИХАЙЛОВ П.В.}

Сибирский государственный университет науки и технологий имени академика М.Ф.

Решетнева, 660037, г. Красноярск, проспект им. газеты Красноярский рабочий, 31

Ключевые слова: сибирский шелкопряд (Dendrolimus sibiricus Tschetv.), Landsat-8, random forest, xgBoost, лесопатологический мониторинг

Аннотация

На основе временных рядов космоснимков Landsat - 8 исследована динамика повреждений темнохвойных лесных формаций, индуцированная вспышкой массового размножения сибирского шелкопряда (Dendrolimus sibiricus Tschetv.). Для выделения использовались спектральные каналы с 1 по 7 (пространственное разрешение 30 м). Классификация проводилась двумя алгоритмами: random forest и XGBoost для трех дат съемки (сентябрь 2018 года, июль и сентябрь 2019 года). Метод показал высокую точность, каппа статистика варьировала от 0,918 до 0,999.

Введение

Популяция сибирского шелкопряд (Dendrolimus sibiricus Tschetv.), является неотъемлемой частью таежных лесных экосистем, закономерно предпочитая определенные наиболее благоприятные условия для существования и функционирования в пространственно-временной динамике.

Как показывает практика на протяжении нескольких десятилетий в большинстве случаев кардинальные меры по уничтожению фитофага предпринимаются по достижении популяции эруптивной стадии, что в конечном итоге не всегда позволяет спасти значительные площади ценных лесных экосистем. Большая часть из них уже представляются погибшими или в перспективе значительно ослабленными насаждениями, не имеющими возможности на восстановление. Известно, что вспышки сибирского шелкопряда, наряду с пожарами, в значительной степени предопределяет ход сукцессионных процессов в таежных лесах $[1,2,3]$.

В связи с существующей проблемой целесообразно совершенствование методов, направленных на раннее обнаружение развития вспышки сибирского шелкопряда. В основе алгоритма должны лежать организационные моменты, связанные с территориальной особенностью существования резерватов популяции, выделенные на основе знаний о биоэкологии фитофага в сочетании с оперативным анализом состояния территории методами дистанционного зондирования Земли $[4,5,6,7,8]$. Кроме того, в случае развития вспышки важна возможность прогнозирования закономерности развития очага, поскольку данный процесс также обусловлен определёнными факторами и не всегда носит хаотический характер $[2,3,9]$.

Целью исследования была оценка точности алгоритма классификации для трех трех наблюдений вспышки массового размножения сибирского шелкопряда, за разное время.

Объект изучения

Объектом изучения являлась область недавней повышенной активности сибирского шелкопряда в границах темнохвойных южных горно-таежных лесов Восточного Саяна 
(Красноярский край). Район исследования расположен в таежной зоне Саянского лесозащитного района и относится к зоне средней лесопатологической угрозы.

Ландшафтный комплекс характеризуется среднегорным рельефом и территориально относится к Южно-Сибирской горной лесорастительной зоне, Алтае-Саянскому горнотаежному лесному району. Климат района резко континентальный и находится под влиянием влажных западных воздушных масс летом и сибирского антициклона зимой. Продолжительность вегетационного периода в среднем составляет 149 - 151 день. Абсолютный минимум температуры в январе - минус 50 0С, абсолютный максимум в июле 38,6 0С. Среднегодовое количество осадков около 527 мм. Преобладающими ветрами являются ветры юго-восточного направления со средней скоростью $2,8-4,7$ м/с [10].

Основной кормовой культурой сибирского шелкопряда в данном районе является пихта сибирская (Abies sibirica L.) и сосна кедровая сибирская - кедр (Pinus sibirica Du Tour). Региональная особенность темнохвойных формаций выражается в господстве зеленомошной группы, представленной целым набором типов леса [11].

Спутниковые снимки и их анализ

Исследование проведено методом ретроспективного анализа на базе геоинформационной системы (GIS) совмещенного с данными дистанционного зондирования Земли Earth Observation (EO) data. Для анализа использовался временной ряд спутниковых снимков Landsat - 8 полученных с геопортала Earth Explorer (https://earthexplorer.usgs.gov/) c пространственным разрешением Ground Sample Distance (GSD) 30 м. В современных исследованиях существуют хорошо зарекомендовавшие себя высокоточные методы классификации поврежденных фитофагами территорий с помощью таких изображений [12, $13,14,15,16]$.

Анализ развития вспышки фитофага проведен за период с июня 2018 по май 2020 гг. Количество сцен по данным космоснимков на определённую дату, демонстрирующих состояние лесов до вспышки и в различных стадиях повреждений популяцией вредителя, приведены в таблице 1.

Таблица 1 - Космические снимки и периоды наблюдений

\begin{tabular}{|l|c|}
\hline \multicolumn{1}{|c|}{ Название файла } & Дата \\
\hline LC08_L1TP_141022_20180812_20180815_01_т1 & 25.06 .2018 \\
\hline LC08_L1TP_141022_20180929_20181009_01_T1 & 29.09 .2018 \\
\hline LC08_L1TP_140022_20190504_20190520_01_T1 & 04.05 .2019 \\
\hline LC08_L1TP_141022_20190730_20190801_01_T1 & 30.07 .2019 \\
\hline LC08_L1TP_140022_20190909_20190917_01_T1 & 09.09 .2019 \\
\hline LC08_L1TP_141022_20200513_20200526_01_T1 & 13.05 .2020 \\
\hline
\end{tabular}

В данной работе представлены сцены наиболее выраженно демонстрирующие пространственно-временную динамику распространения сибирского шелкопряда в границах исследуемой территории. Фрагмент снимка включающий зону поврежденных древостоев ограничен координатами 54,69600 с. ш., 95,74550 в. д.; 55,17220 с. Ш., 95,34970 в. д.; 55,17490 с. ш., 96,29150 в. д.; 54,69600 с. ш., 96,29120 в. д.

Обработка ДЗ3 выполнялась в программе R (v4.0.2) (https://www.r-project.org). Это свободная программная среда для статистических вычилслений и создания графики. Для визуального анализа ДЗ3 применялась программа QGIS (v3.10) (https://qgis.org).

На подготовительном этапе проводился визуальный анализ участков поврежденных сибирским шелкопрядом. Основным источником данных являлись Д33 Landsat-8 за 29.09.2018, 30.07.2019 и 09.09.2019. Снимки уровня обработки L2 были получены с сайта геологической службы США (U.S. Geological Survey) (https://earthexplorer.usgs.gov/). Облака и тени облаков со снимков были удалены во время подготовки данных. Для полного 
покрытия исследуемой области снимки за одну и ту же дату были склеены и перепроецированы в географическую систему координат WGS84. Для лучшей видимости повреждений использовалась следующая комбинация каналов: красный - 7 канал; зеленый 5 канал; синий - 3 канал. При таком сочетании каналов поврежденные сибирским шелкопрядом области отображались малиновым цветом, темнохвойные насаждения - темнозеленым, лиственные и светлохвойные насаждения - светло-зеленым. Такое соответствие было установлено в результате проведения полевых работ. При таком способе дистанционного зондирования становится возможным определить древостои поврежденные на $50 \%$ и более.

Для создания маски поврежденных насаждений применялись два популярных алгоритма классификации: "random forest" и "xgBoost" которые реализованы в пакете caret (v6.0-86) для языка R. Целью классификации было разделить пиксели каждого снимка на два класса - поврежденные сибирским шелкопрядом насаждения и все остальные. На снимках выделялись площади одного и другого типа на основе визуальной оценки ДЗ3. Из выделенных полигонов формировалась выборка, которая разделялась на обучающую и проверочную с соотношением 75/25 соответственно. В классификации участвовали с 1 по 7 канал Д33 каждый из которых имел пространственное разрешение 30 м. Для каждой даты съемки параметры классификатора подбирались отдельно путем максимизации критерия Каппа. Для поиска гиперпараметров использовалась перекрестная проверка (cv) c разделением обучющей выборки на 7 блоков (folds). В результате получено 2 модели "xgBoost" и одна модель "random forest". Точность классификации представлена в виде основных статистических показателей в таблице 2.

Таблица 2 - Статистические показатели алгоритмов классификации

\begin{tabular}{|c|c|c|c|c|c|c|}
\hline Дата & $\begin{array}{c}\text { Площадь } \\
\text { повреждений, } \\
\text { га }\end{array}$ & $\begin{array}{c}\text { Алгоритм } \\
\text { классификации }\end{array}$ & Точность & $\begin{array}{c}\text { Чувстви- } \\
\text { тельность }\end{array}$ & $\begin{array}{c}\text { Специфич- } \\
\text { ность }\end{array}$ & $\begin{array}{c}\text { Каппа } \\
\text { статистика }\end{array}$ \\
\hline 29.09 .2018 & 109.7 & xgboost & 1.000 & 1.000 & 0.886 & 0.918 \\
\hline 30.07 .2019 & 3459.6 & xgboost & 0.998 & 0.999 & 0.988 & 0.981 \\
\hline 09.09 .2019 & 17603.3 & random forest & 1.000 & 1.000 & 1.000 & 0.999 \\
\hline
\end{tabular}

В результате обучения моделей получены следующие параметры: 29.09.2018 (xgboost: nrounds $=600$, max_depth $=20$, eta $=0.1$, gamma $=0$, colsample_bytree $=0.9$, min_child_weight $=1$, subsample $=1$ ); 30.07.2019 (xgboost: nrounds $=900$, max_depth $=5$, eta $=0.1$, gamma $=0$, colsample_bytree $=0.9$, min_child_weight $=1$, subsample $=1) ; 09.09 .2019$ (random forest: mtry $=$ 4 , ntree $=500$ ).

\section{Заключение}

Современные алгоритмы машинного обучения, такие как random forest и xgboost возможно применять для выделения древостоев с поврежденным ассимиляционным аппаратом. В ходе исследования алгоритмы показали свою эффективность, что подтверждается высокими значениями каппа статистики. Есть перспектива использовать алгоритмы для выделения и других поврежденных насаждений.

\section{Литература}

1. Исаев А.С., Е.Н. Пальникова, В.Г. Суховольский, О.В. Тарасов Динамика численности лесных насекомых-филлофагов: модели и прогнозы. М.: Товарищество научных изданий КМК, 2015. - 262 с. 
2. Рожков А.С. Массовое размножение сибирского шелкопряда и меры борьбы с ним. М.: Наука, 1965. - 179 с.

3. Кондаков Ю.П. Закономерности массовых размножений сибирского шелкопряда. Экология популяций лесных животных Сибири, Новосибирск: Наука, 1974, С. 206 - 264.

4. Методы мониторинга вредителей и болезней леса / Под общ. ред. В.К. Тузова. - М.: ВНИИЛМ, 2004. - 200 с.

5. Лямцев Н.И. Прогнозирование массовых размножений непарного шелкопряда, угрозы повреждения дубрав и необходимости защитных мероприятий, Пушкино: ВНИИЛМ, 2018. $-84 \mathrm{c}$.

6. Egan, J.M.; Kaiden, J.; Lestina, J.; Stasey, A.; Jenne, J.L. Techniques to Enhance Assessment and Reporting of Pest Damage Estimated with Aerial Detection Surveys; R1-19-09; U.S. Department of Agriculture, Forest Service, Northern Region, Forest Health Protection: Missoula, MT, USA, 2019; p. 33.

7. Mukul M, Srivastava V, Mukul M (2015) Analysis of the accuracy of Shuttle Radar Topography Mission (SRTM) height models using International Global Navigation Satellite System Service (IGS) Network. Journal of Earth System Science 124(6): 1343-1357. https://doi.org/10.1007/s12040-015-0597-2

8. Insect \& Disease Detection Survey (IDS) Data Downloads. Available online: https://www.fs.fed.us/foresthealth/applied-sciences/mapping-reporting/detection-surveys.shtml (accessed on 5 August 2020).

9. Флоров Д.Н. Вредитель сибирских лесов, Иркутск: ОГИЗ, 1948. - 143 С.

10. Поликарпов Н.П., Чебакова Н.М., Назимова Д.И. Климат и горные леса Южной Сибири. - Новосибирск: Наука, 1986 - 227 с.

11. Смагин В.Н., Ильинская С.А., Назимова Д.И., Новосельцева И.Ф., Чередникова Ю.С.. Типы лесов гор Южной Сибири. Новосибирск, «Наука», 1980 - 336 с.

12. Benjamin C. Bright, Andrew T. Hudak, Joel M. Egan, Carl L. Jorgensen, Franciel E. Rex, Jeffrey A. Hicke, and Arjan J.H. Meddens Using Satellite Imagery to Evaluate Bark Beetle-Caused Tree Mortality Reported in Aerial Surveys in a Mixed Conifer Forest in Northern Idaho, USA. Forests 2020, 11(5), 529. Available online: https://doi.org/10.3390/f11050529

13. Wulder, M.A.; Dymond, C.C.; White, J.C.; Leckie, D.G.; Carroll, A.L. Surveying mountain pine beetle damage of forests: A review of remote sensing opportunities. For. Ecol. Manag. 2006, 221, 27-41. [Google Scholar] [CrossRef]

14. Meddens, A.J.H.; Hicke, J.A.; Vierling, L.A. Evaluating the potential of multispectral imagery to map multiple stages of tree mortality. Remote Sens. Environ. 2011, 115, 1632-1642. [Google Scholar] [CrossRef]

15. 4.Bright, B.C.; Hicke, J.A.; Hudak, A.T. Estimating aboveground carbon stocks of a forest affected by mountain pine beetle in Idaho using lidar and multispectral imagery. Remote Sens. Environ. 2012, 124, 270-281. [Google Scholar] [CrossRef]

16. Townsend PA, Singh A, Foster JR, et al. (2012) A general Landsat model to predict canopy defoliation in broadleaf deciduous forests. Remote Sensing of Environment 119: 255-265. https://doi.org/10.1016/j.rse.2011.12.023

Работа выполнена в рамках государственного задания Минобрнауки России на выполнение коллективом научной лаборатории «Защита леса» проекта «Фундаментальные основы защиты лесов от энтомо- и фитовредителей в Сибири» (№ FEFE-2020-0014) 